\title{
Amino-acid substitutions in acetylcholinesterase 1 involved in insecticide resistance in mosquitoes
}

\author{
H. Alout*, M. Weill
}

Institut des Sciences de l'Evolution (UM2-CNRS), Université Montpellier 2, Team Genetics of Adaptation, Laboratoire Génétique et Environnement, Place Eugène Bataillon, CC 065, 34095 Montpellier 05, France

\section{A R T I C L E I N F O}

\section{Article history:}

Available online 10 April 2008

\section{Keywords:}

Acetylcholinesterase

Resistance

Insecticide

Mosquito

\begin{abstract}
A B S T R A C T
In natural populations of mosquitoes, high level of resistance to carbamates (CX) and organophosphates (OP) is provided by insensitive acetylcholinesterase (AChE1). Different alleles conferring resistance have been identified at the ace 1 locus. They differ from the wildtype by only one amino-acid substitution. The comparison of the biochemical characteristics of mutated recombinant proteins and AChE1 in resistant mosquito extracts confirmed the role of each substitution in insensitivity. Selection of these different resistant alleles in field populations depends likely on the insecticides used locally. Theoretical modelling studies are initiated to develop novel strategies of mosquito control.
\end{abstract}

(c) 2008 Elsevier Ireland Ltd. All rights reserved.

\section{Introduction}

Mosquitoes are among the most important vectors of human disease. The use of insecticide to control them has led to selection of resistant populations and hence to control program failures. In many arthropods, selection of insensitive insecticide target is a common resistance mechanism. This is the case of acetylcholinesterase (AChE, EC 3.1.1.7), the target of OP and CX insecticides. In Diptera, two AChE genes are usually present (ace-1 and ace-2), and ace 1 codes the synaptic enzyme [1]. In a few Diptera, such as true flies, only the ace- 2 gene is present and codes the synaptic AChE [2]. In mosquitoes, a single aminoacid change, located near the active site of the synaptic AChE1, is sufficient to provide a high resistance level. To date, only three single amino-acid substitutions have been described: G119S in Culex pipiens, C. vishnui, Anopheles gambiae and A. albimanus; F290V in C. pipiens and F331W in C. tritaeniorhynchus (according to Torpedo californica AChE nomenclature), suggesting a very high structural constraint of the AChE1 enzyme [3-5]. These substitutions have been

\footnotetext{
* Corresponding author. Fax: +33467144657.

E-mail address: alout@isem.univ-montp2.fr (H. Alout).
}

shown to provide insensitivity by means of in vitro experiments with mutated recombinant enzymes [3,4,6,7]. Our aim is to understand how resistance-associated mutations are selected in natural populations in order to delay its occurrence and its spread. The present study focuses on characterization of mutated recombinant AChE1 proteins and their biochemical properties. Preliminary data are presented.

\section{Materials and methods}

\subsection{Mosquito samples}

Two C. pipiens reference strains were used: the susceptible one SLAB [8] and the resistant homozygous G119S SR [9]. ACE-R strain homozygous for the F290V mutation was established from the Mitsero population collected in Cyprus in 1987 [10]. C. tritaeniorhynchus larvae harboring the F331W AChE1 were sampled in China in 2003 [6].

\subsection{Site-directed mutagenesis}

Expression vectors pAc5.1/V5-His (Invitrogen) containing C. pipiens WT and G119S AChE1 complete coding 

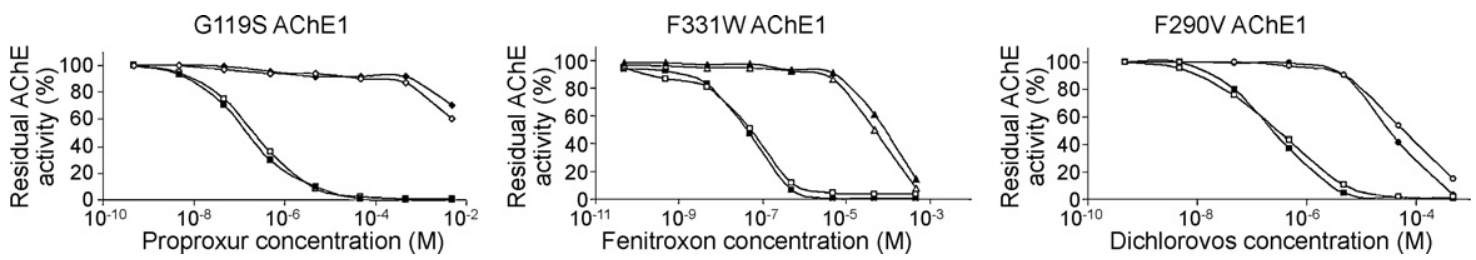

Fig. 1. Comparison of residual AChE1 activities of recombinant enzymes (black symbols) and mosquito head extracts (empty symbols) in presence of increasing doses of insecticides. For each mutated AChE1, only one insecticide is represented. Residual activity of susceptible head extract and WT recombinant AChE1 are included as control (squares).

sequences were already described [3]. Mutations were introduced into the WT vector by means of a PCR-based strategy $[4,6]$.

\subsection{Production of wild-type and mutated AChE1 in Drosophila S2 cells}

S2 cells $\left(20 \times 10^{6}\right)$ were transfected using Fugene6 (Roche), in OptiMEM medium, according to the manufacturer protocol. Cells were maintained in serum-free Schneider's medium to prevent AChE activity from foetal bovine serum. Four days after transfection, cells were collected by centrifugation at $250 \times \mathrm{g}$ for $3 \mathrm{~min}$ and homogenised in $500 \mu \mathrm{l}$ phosphate buffer $(0.25 \mathrm{M}, \mathrm{pH} 7.0)$ containing $1 \%$ Triton X-100. The homogenate was centrifuged for $10 \mathrm{~min}$ at $9000 \times g$ and the supernatant was used as source of enzyme, after dilution in phosphate buffer.

\subsection{AChE1 inhibition characteristics}

The relative AChE1 activity was determined spectrophotometrically at room temperature, as described by Ellman et al. [11], using $100 \mu \mathrm{l}$ of supernatant containing the recombinant AChE1 WT, G119S, F331W or F290V. Inhibition curves were performed by incubating samples $(100 \mu \mathrm{l})$ for 15 min with $10 \mu \mathrm{l}$ of inhibitor solutions at various concentrations. We then added $100 \mu \mathrm{l}$ of $1.6 \mathrm{mM}$ substrate and residual AChE1 activity was estimated by measuring changes in optical density at $412 \mathrm{~nm}$ for $15 \mathrm{~min}$. We analysed three to five replicates for each assay. Replicates were performed with distinct batches of production.

The irreversible inhibition reaction is pseudo-first order and the residual activity follows the equation $[E] /\left[E_{0}\right]=$ $\mathrm{e}^{-k_{i} t\left[I_{0}\right]}$, when inhibitors are in excess compared to enzyme. $k_{i}$ is the bimolecular rate constant, $t$ represents time of incubation and $\left[I_{0}\right]$ is the initial inhibitor concentration. Insensitivity ratios were calculated by dividing the $k_{i}$ of wild-type (WT) recombinant AChE1 by the $k_{i}$ of mutated recombinant AChE1.

\subsection{Three-dimensional modelling}

Three-dimensional structures of AChE1 were created by automated homology modelling using $T$. californica and $D$. melanogaster AChE as previously described [12]. RMS deviation is $1.1 \AA$ on 528 carbon atoms.

\section{Results and discussion}

Different insensitive AChE1 were characterized on individual mosquitoes from different field samples using the biochemical TPP test [13]. The cDNA of ace1 were then sequenced from homozygous resistant individuals and compared with susceptible ones. Once identified, the mutations were introduced into an expression vector containing the wild-type ace 1 cDNA to produce the mutated recombinant enzymes in Drosophila S2 cells. Then, sensitivity to 10 insecticides was investigated to compare the recombinant AChE1s with the enzyme extracted from resistant mosquito heads (Fig. 1). The superimposition of inhibition patterns of recombinant and mosquito extracted enzymes for all insecticides (data not shown) confirmed the role of each AChE1 mutation in resistance. The different mutated AChE1 displayed a strong insensitivity to specific insecticides (Table 1), and there was a good relationship between the highest insensitivities (resistance ratios) and the insecticide(s) used locally in control programs. Thus, F290V allele was observed in resistant $C$. pipiens sampled in Cyprus Island where the main insecticide used is dichlorvos. F331W is the resistant allele found in C. tritae-

Table 1

Bimolecular velocity constant $\left(k_{i}\right)$ and resistance ratio to organophosphates and carbamate insecticides observed in wild-type (WT) and mutated AChE1

\begin{tabular}{|c|c|c|c|c|c|c|c|c|}
\hline \multirow[t]{2}{*}{ Pesticide class } & \multirow[t]{2}{*}{ Insecticide } & \multicolumn{4}{|c|}{$k_{i}(1 / \mathrm{mol} / \mathrm{s})$} & \multicolumn{3}{|c|}{ Resistance ratio (WT/mutant) } \\
\hline & & WT & G119S & F290V & F331W & G119S & F290V & F331W \\
\hline \multirow[t]{3}{*}{ Carbamates } & Aldicarb & 167 & 50 & 7 & $\mathrm{~N} / \mathrm{A}$ & 3 & 25 & - \\
\hline & Propoxur & 2895.4 & 0.029 & 58 & 49.4 & 99624 & 50 & 59 \\
\hline & Eserine & 48135.2 & 948.5 & 8852 & 1006.7 & 51 & 5 & 48 \\
\hline \multirow[t]{6}{*}{ Organophosphorous } & Dichlorvos & 1711.5 & 373.9 & 25 & 11.2 & 5 & 68 & 153 \\
\hline & Malaoxon & 3209.01 & 43.03 & 372 & 60.6 & 75 & 9 & 53 \\
\hline & Paraoxon-ethyl & 4557.2 & 37.9 & 917 & 381.3 & 120 & 5 & 12 \\
\hline & Paraoxon-methyl & 6261.5 & 26.5 & $\mathrm{~N} / \mathrm{A}$ & 217.6 & 237 & - & 29 \\
\hline & Fenitroxon & 17114.7 & 252.5 & 181 & 16.2 & 68 & 95 & 1053 \\
\hline & Chlorpyrifos-oxon & 54236.9 & 89.9 & 14531 & 3500.7 & 604 & 4 & 15 \\
\hline
\end{tabular}


(a)

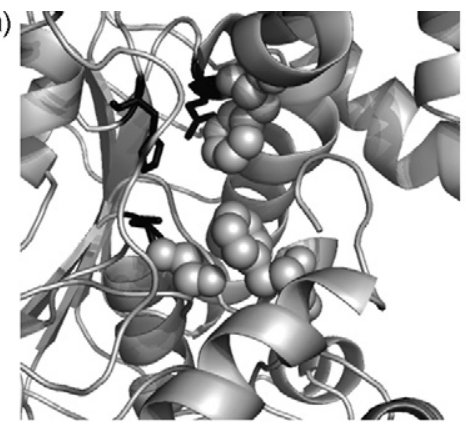

(b)

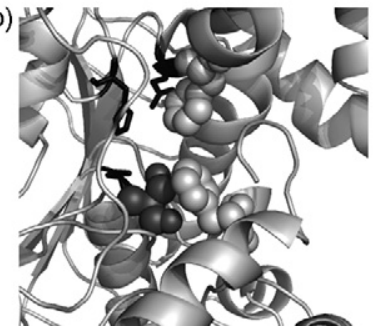

(c)

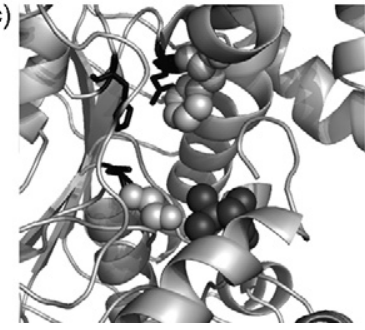

(d)

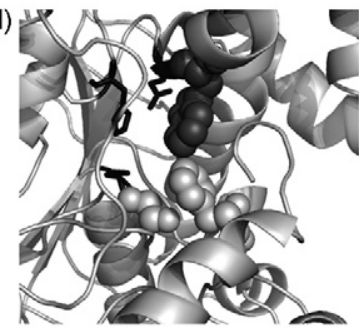

Fig. 2. 3D view point of the entrance of the catalytic gorge of AChE1. The backbone of the enzyme structure is rendered as ribbon with secondary structure. (a) The catalytic triad is represented as black sticks. G119, F290, F331 are represented as light grey van der Waals spheres. Amino-acid substitutions are represented in dark grey: (b) the G119S, (c) the F290V and (d) the F331W.

niorhynchus from China where the species is controlled by the use of fenitrothion and dichlorvos. G119S resistant allele was found in C. pipiens from France, where chlorpyrifos has been the only insecticide used to control this species until the late 1990s.

Using a structural model of $C$. pipiens AChE1 created by automated homology, the mutated positions were located. The 119 position is close to the catalytic Serine (S200) and the G-to-S substitution would reduce accessibility to inhibitors and substrate by steric hindrance (Fig. 2b). F331 is implicated in substrate guidance, as a component of the choline binding site (Fig. 2c). Substitution affecting this position would alter stabilization of intermediates. Also due to its bigger size, tryptophane residue might reduce accessibility for other ligands [14]. The F290 (Fig. 2d) belongs to the acyl binding pocket and is involved in substrate specificity. Although this substitution involved a residue smaller than the $\mathrm{WT}$, it might hamper the gorge entrance because of a loss of stabilization process [15]. These residues are important features of cholinesterases, particularly of acetylcholinesterase which has been naturally selected for its high catalytic activity. Therefore, these mutations in AChE may affect normal cholinergic function leading to a selective disadvantage as demonstrated for the G119S AChE1 in C. pipiens [16]. Further work includes the determination of specific activity and enzymatic stability to estimate relative selective value, and crystallization for structural studies.

\section{Acknowledgements}

This work was financed in part by the ANR Programme SEST "Morevol" (Ministère délégué à la Recherche). Contribution 2007-032 of the Institut des Sciences de l'Evolution de Montpellier (UMR CNRS 5554).

\section{References}

[1] M. Weill, P. Fort, A. Berthomieu, M.P. Dubois, N. Pasteur, M. Raymond, A novel acetylcholinesterase gene in mosquitoes codes for the insecticide target and is non-homologous to the ace gene in Drosophila, Proc. R. Soc. Lond. B Biol. Sci. 269 (2002) 2007-2016.

[2] E. Huchard, M. Martinez, H. Alout, E.J.P. Douzery, G. Lutfalla, A. Berthomieu, C. Berticat, M. Raymond, M. Weill, Acetylcholinesterase genes within the Diptera: takeover and loss in true flies, Proc. R. Soc. Lond. B Biol. Sci. 273 (2006) 2595-2604.

[3] M. Weill, G. Lutfalla, K. Mogensen, F. Chandre, A. Berthomieu, C. Berticat, N. Pasteur, A. Phillips, P. Fort, M. Raymond, Insecticide resistance in mosquito vector, Nature 423 (2003) 136-137.

[4] H. Alout, A. Berthomieu, A. Hadjivassilis, M. Weill, A new amino-acid substitution in acetylcholinesterase 1 confers insecticide resistance to Culex pipiens mosquitoes from Cyprus Island, Insect Biochem. Mol. Biol. 37 (2007) 41-47.

[5] T. Nabeshima, A. Mori, T. Kozaki, Y. Iwata, O. Hidoh, S. Harada, S. Kasai, D. Severson, Y. Kono, T. Tomita, An amino acid substitution attributable to insecticide-resistance in a Japanese encephalitis vector mosquito, Culex tritaeniorhynchus, Biochem. Biophys. Res. Commun. 313 (2004) 794-801.

[6] H. Alout, A. Berthomieu, F. Cui, Y. Tan, C. Berticat, C. Qiao, M. Weill, Different amino-acid substitutions confer insecticide resistance through acetylcholinesterase 1 insensitivity in Culex vishnui and Culex tritaeniorhynchus (Diptera: Culicidae) mosquitoes from China, J. Med. Entomol. 44 (2007) 463-469.

[7] J. Benting, R. Nauen, Biochemical evidence that an S431F mutation in acetylcholinesterase-1 of Aphis gossypii mediates resistance to primicarb and omeothoate, Pest Manag. Sci. 60 (2004) 1051-1055.

[8] G.P. Georghiou, R.L. Metcalf, F.E. Gidden, Carbamates-resistance in mosquitoes; selection of Culex pipiens fatiguans Wied (=Culex quinquefasciatus) for resistance to Baygon, WHO 35 (1966) 691-708.

[9] C. Berticat, G. Boquien, M. Raymond, C. Chevillon, Insecticide resistance genes induce a mating competition cost in Culex pipiens mosquitoes, Genet. Res. 79 (2002) 41-47.

[10] M.C. Wirth, G.P. Georghiou, Organophosphate resistance in Culex pipiens from Cyprus, J. Am. Mosq. Control Assoc. 12 (1996) 112-118.

[11] G.L. Ellman, K.D. Courtney, V. Andres, R.M. Featherstone, A new and rapid colorimetric determination of acetylcholinesterase activity, Biochem. Pharmacol. 7 (1961) 88-95.

[12] M. Weill, C. Malcolm, F. Chandre, K. Mogensen, A. Berthomieu, M. Marquine, M. Raymond, The unique mutation in ace-1 giving high insecticide resistance is easily detectable in mosquito vectors, Insect Mol. Biol. 13 (2004) 1-7. 
[13] D. Bourguet, N. Pasteur, J. Bisset, M. Raymond, Determination of Ace.1 genotypes in single mosquitoes: toward an ecumenical biochemical test, Pest. Biochem. Physiol. 55 (1996) 122-128.

[14] A. Ordentlich, D. Barak, C. Kronman, Y. Flashner, M. Leitner, Y. Segall, N. Ariel, S. Cohen, B. Velan, A. Shafferman, Dissection of the human acetylcholinesterase active center determinants of substrate specificity. Identification of residues constituting the anionic site, the hydrophobic site and the acyl pocket, J. Biol. Chem. 268 (1993) 17083-17095.
[15] M. Harel, J.L. Sussman, E. Krejci, S. Bon, P. Chanal, J. Massoulie, I. Silman, Conversion of acetylcholinesterase to butyrylcholinesterase - modeling and mutagenesis, PNAS 22 (1992) 1082710831.

[16] M. Raymond, C. Berticat, M. Weill, N. Pasteur, C. Chevillon, Insecticide resistance in the mosquito Culex pipiens: what have we learned about adaptation? Genetica 112-113 (2001) 287-296. 